\title{
Hartley Albino Hairless Guinea Pig
}

National Cancer Institute

\section{Source}

National Cancer Institute. Hartley Albino Hairless Guinea Pig. NCI Thesaurus. Code C77089.

Derived from inbred Hartley stocks at the Eastman Kodak Company and Montreal's Institute Armand Frappier, having undergone spontaneous mutation that led to hairlessness and athymicity. The mutation that spawned the Hartley Hairless Guinea Pig was then re-derived at Charles River to restore thymus function while maintaining hairlessness. The skin of the Hartley Hairless guinea pig resembles many physical and physiological aspects of human skin and spontaneous formation of melanoma is common to this strain. It is therefore used in a variety of pre-clinical dermatological studies. 